\title{
The relationships among critical thinking disposition, caring behavior, and learning styles in student nurses
}

\author{
Hsiang-Chu Pai ${ }^{1 *}$, Cheng-Joo Eng ${ }^{2}$ \\ ${ }^{1}$ Department of Nursing, Min-Hwei College of Health Care Management, Taiwan \\ ${ }^{2}$ Department of Child-Educare, Min-Hwei College of Health Care Management, Taiwan \\ Email: pai55215@ms41.hinet.net
}

Received 2 March 2013; revised 5 April 2013; accepted 15 May 2013

Copyright (C) 2013 Hsiang-Chu Pai, Cheng-Joo Eng. This is an open access article distributed under the Creative Commons Attribution License, which permits unrestricted use, distribution, and reproduction in any medium, provided the original work is properly cited.

\begin{abstract}
The purpose of this study was to identify the relationships among disposition toward critical thinking, learning styles, and caring behaviors in student nurses enrolled in three 5 -year junior nursing colleges in Southern Taiwan. Methods: This cross-sectional study used a convenience sample that comprised 777 nursing students from two cities. The data were obtained through the Critical Thinking Disposition Inventory, Chinese Version (CTDI-CV), Index of Learning Styles (ILS), and the Caring Behavior Scale (CBS). The sample ranged in age from 16 to 22 years $(M=18.21)$. Results: Students scored highest on the inquisitiveness subscale and lowest on the truth-seeking subscale. Additionally, some dimensions of disposition toward critical thinking differed significantly by learning style. There was a positive relationship between overall critical thinking dispositions and caring behaviors $(r=0.23, p<0.01)$. Finally, dimensions of caring behavior, with the exception of the maturity dimension, were significantly positively related to most dimensions of the disposition toward critical thinking $(p<$ 0.05). Conclusion: The findings indicate that not only is learning style related to critical thinking disposition but also to caring behaviors. However, the cause of these relationships warrants further study.
\end{abstract}

Keywords: Caring Behavior; Critical Thinking Disposition; Student Nurse

\section{INTRODUCTION}

Nursing is a profession that calls for complex behaviors. The responsibilities of practitioners include physical, psychological, mental, and spiritual care for a variety of

"Corresponding author. clients. In addition, in this modern healthcare environment, with its complex technology and patient interventions, nurses require critical thinking skills. Therefore, many studies have emphasized the need for critical thinking and have identified the relationships between disposition toward critical thinking and learning style [1-5]. Generally, such studies have found that, to improve students' critical thinking, teaching strategies need to be guided by an assessment of students' learning style. Nevertheless, Thompson and Crutchlow [3] have argued that, although learning style may have some influence or effect on the teaching/leaning process, educators "may be focusing on students' style when planning strategies while ignoring other factors that are equally as or more important than style" (p. 34). Until recently, much of the research on critical thinking among nurses has focused on learning style instead of caring behavior. As such, there is a gap in our understanding of the dimensions of disposition toward critical thinking as related to certain behaviors, specifically caring, which is the core of nursing.

Disposition toward critical thinking is a vital component of professional clinical judgment. Thus, the Taiwan Nursing Accreditation Council advocates critical thinking as an indicator of success in higher nursing education [6]. Several studies have begun to focus on the disposition toward critical thinking across culture [7,8]. Dunn [9] defined learning style as "the way in which each person absorbs and retains information and/or skill; regardless of how that process is described, it is dramatically different for each person" (p. 12). Several studies on the development of disposition toward critical thinking have identified learning styles as playing a role [1-5]. Colucciello noted that behavioral dispositions, personality, interests, and choices are influenced by one's learning style [1]. In fact, Colucciello's study found a correlation between critical thinking dispositions and dimensions of 
learning style [1], and Suliman's research had similar findings [2]. In keeping with this, recently research has shown that only the self-confidence factor of disposition toward critical thinking was significantly correlated with the sensing-intuitive and visual-verbal learning styles [5]. Based on the research, it is clear that learning style has some influence on the disposition toward critical thinking, but not overall or always. Overall, there was a weak, although significant, correlation between learning style and disposition toward critical thinking.

Among nursing paradigms, caring behavior plays a key role in the disposition toward critical thinking. Thayer-Bacon emphasized that caring is necessary to being a critical thinker, especially when one has not had the same life experiences as another person [10]. Watson stated, "Caring is the roar that lies on the other side of silence [11]. When the mist lifts, nurses can find a new image of caring" (p. 16). Caring stimulates critical thinking and is related to more comprehensive judgment [12]. As Swanson has noted [13], nurses who are well informed about patients elevate patients' well-being through their concern for the patient. Nursing knowledge is seen in caring behaviors [13]. As Thayer-Bacon has noted [10], caring behavior is the particular way in which an individual is willing to attend to what another is feeling, enabling the caring individual to exercise critical thinking. Redding also described that the process of clinical judgment as involving caring [14].

Thus, the aims of this study are to examine the relationships among disposition toward critical thinking, learning styles, and caring behaviors in student nurses as well as to assess the role of caring behaviors for critical thinking disposition. The results can be used to develop targeted interventions. The constructive thinking model of Thayer-Bacon [10] was used as the framework for understanding the relationship between caring and critical thinking disposition in this study. This model posits that, to be a critical thinker, caring is a necessary disposition, especially when ideas and arguments do not have a life of their own. Thus, caring can help to ensure that ideas have been fairly considered and understood and can contribute to a person being a good critical thinker. Based on the constructive thinking model and the literature, we hypothesize that critical thinking is not only related to learning style but also to caring behavior. Thus, the study sought to answer the following questions:

1) What are the dispositions toward critical thinking, learning styles, and caring behaviors of nursing students?

2) What are the differences in dispositions toward critical thinking related to learning styles?

3) What is the relationship between caring behavior and disposition toward critical thinking?

\section{METHOD}

\subsection{Design and Sample}

This cross-sectional study used a convenience sample $(N$ $=777$ ) that comprised students from three 5 -year junior nursing colleges located in southern Taiwan. These colleges, similar to community colleges, provide vocational education and training. Participants were recruited from Year-4 and Year-5 classes for each college, with a sample of three classes from each year. Data collection occurred during the regularly scheduled curriculum. A total of 822 questionnaires (as described in the Instruments section below) were collected; however, 45 were excluded from the analysis due to missing data. The final sample consisted of 777 students, for a response rate of $94.52 \%$ (Year 4: $n=504$; Year 5: $n=273$ ), most of whom $(96.3 \%)$ were female. The participants ranged in age from 16 to 22 years, with a mean age of 18.21 years. All participants had one month of clinical practice experience.

\subsection{Instruments}

Three instruments were used to collect the data.

Critical Thinking Disposition Inventory, Chinese Version (CTDI-CV). The CTDI-CV consists of 70 statements, 10 each for the seven dispositions, intended to measure participants' critical thinking characteristics: truth-seeking, open-mindedness, analyticity, systematicity, self-confidence, inquisitiveness, and maturity [15]. The CTDI-CV has conceptual equivalence with the California Critical Thinking Disposition Inventory (CCTDI) [16]. The items are rated on a 6-point Likert scale, ranging from 1 (strongly disagree) to 6 (strongly agree). Each subscale score ranges from 10 to 60 , with a possible range of overall scores of 70 to 420 ; higher scores reflect a greater disposition toward critical thinking. Facione, Facione, and Giancario [17] suggested that a score of at least 40 indicates the strong (positive) presence of a characteristic. Scores from 31 to 39 indicate an ambivalent inclination. For the overall CTDI-CV, a score of at least 280 indicates positive critical thinking abilities. Scores of 350 or more indicate a strong disposition toward critical thinking [17-19]. Peng et al. reported that the subscale Cronbach's alphas ranged from [15] 0.54 to 0.77 , with an overall alpha of 0.90 . In this study, the coefficient alphas of the CTDI-CV subscales ranged from 0.52 to 0.73 , and the overall alpha was 0.90 .

Index of Learning Styles (ILS). The ILS is a 44-item, self-report inventory designed to measure preferences in 8 categories across 4 dimensions (active/reflective, sensing/intuitive, visual/verbal, and sequential/global) of learning style [20]. As reflected in the ILS, active learners prefer to learn via teamwork and collaboration. Reflective learners prefer to complete tasks alone and usually 
think and learn individually. Sensing learners are concerned that learning relate to the real world and prefer to learn concrete facts and knowledge. Intuitive learners prefer to understand possibilities and the relationships between things, are fond of completing things in a fast and innovative way, and dislike doing things repeatedly. Visual learners learn effectively from figures, tables, diagrams, charts, timetables, movies, or actual operations. Verbal learners learn best from verbal description or oral explanation. Sequential learners prefer to learn by following a prescribed order and thinking logically to find the answer. Global learners prefer to learn by lateral learning and find it difficult to learn until they have grasped the "big picture", after which they are able to fill in the details.

Each learning style dimension consists of 11 items, for which there are two possible responses ( $a$ or $b$ ). These two responses correspond to one or the other category of the learning style dimension (e.g., active or reflective). The scoring method counts $a$ responses, so that a score on a dimension would be an integer ranging from 0 to 11 . "Using the active-reflective dimension as an example, 0 or 1 ' $a$ ' responses would represent a strong preference for reflective learning, 2 or 3 a moderate preference for reflective, 4 or 5 a mild preference for reflective, 6 or 7 a mild preference for active, and 10 or 11 a strong preference for active" [21]. This method of scoring was used in all of the statistical analyses. In this study, the ILS (Chinese version) was used to assess learning style [22]. The ILS has been administered to Chinese students, for whom subscale internal consistency reliability coefficients ranged from 0.50 to 0.62 . For this study, reliability was found to range from 0.48 to 0.51 .

Caring Behavior Scale (CBS). The CBS was designed by Lin [23] to measure caring behavior when providing healthcare in three areas (three subscales): helping the patient through the illness trajectory, knowing the patient, and patient advocacy. The scale consists of 28 items, with each subscale containing 9 to 10 statements. The participant is asked to assign a score, ranging from 3 to 0 , for each statement in each item, with 3 representing "always" and 0 representing "never". Each subscale score ranges from 0 to 27 or 0 to 30 , and the possible range of overall scores is 0 to 84 , with higher scores reflecting greater caring behaviors. The CBS has been found reliable and valid $[23,24]$. In the current study, Cronbach's alpha coefficient for the CBS was 0.95 , which is consistent with what was reported in a previous study [24]. The CBS's subscales coefficient alphas were $0.89,0.88$, and 0.88 , respectively.

\subsection{Data Analysis}

Data analysis was conducted using SPSS, Version 18.0.
Descriptive statistics (frequencies, means, and standard deviations) and inferential statistics (partial correlations and Student's $t$-tests) were used. Student's $t$-tests were used to determine the differences in disposition toward critical thinking based on learning styles. Partial correlation coefficients (age controlled) were used to test the relationship between caring behavior and disposition toward critical thinking dispositions.

\subsection{Ethical Considerations}

The Institutional Research Board of the participating colleges approved the study. Students received a formal explanation before participating in the study. Those who agreed to participate signed a consent form. Participation was voluntary, and all data were confidential and anonymous.

\section{RESULTS}

\subsection{Participant Disposition toward Critical Thinking}

The means and standard deviations for each of the seven critical thinking dispositions and the total mean score are presented in Table 1. CTDI scores ranged from 206 to 364 ; 489 students $(62.93 \%)$ scored below 280, 280 students $(36.04 \%)$ scored between 280 and 350, and only 8 students $(0.01 \%)$ scored above 350 . The findings showed that the overall sample mean score $(M=275.29)$ is marginally low. The overall sample mean of the subscales was lower than the cutoff point of 40, with truth-seeking rated the lowest $(M=35.39)$. Three characteristics, however, had means greater than 40: open-mindedness $(M=41.08)$, analyticity $(M=41.98)$, and inquisitiveness $(M=43.37)$ but were still lower than the target score of 50 . Students in the two groups (year 4 and year 5) showed no statistically significant difference in CTDI scores $(t=$ $1.854, p=0.064)$. There also were no statistical significant differences in the relationship between age and CTDI $(r=0.03, p=0.39)$.

As also shown in Table 1, the mean scores for helping the patient through the illness trajectory $(M=18.19)$, knowing the patient $(M=15.56)$, and patient advocacy $(M=16.41)$ were above the middle of the range of scores (0 - 30), indicating a moderate level of caring behaviors.

\subsection{Learning Style and Caring Behaviors}

The learning styles of the sample are shown in Table 2. Of the 777 respondents who completed the learning style measurement, 446 (57.4\%) were active learners, while $331(42.6 \%)$ were reflective learners. For the second learning style dimension, 588 students $(75.7 \%)$ were identified as sensing learners and $189(24.3 \%)$ as intuitive learners. For the third learning style dimension, which 
Table 1. Critical thinking dispositions and caring behaviors scores.

\begin{tabular}{ccccccc}
\hline & Variable & Min. & Max. & Mean & $S D$ & $95 \%$ CI \\
\hline Critical Thinking & & & & & & \\
\hline & Truth-seeking & 10 & 54 & 35.39 & 5.79 & $34.98-35.79$ \\
& Open-mindedness & 25 & 55 & 41.08 & 5.12 & $40.72-41.44$ \\
& Analyticity & 29 & 59 & 41.98 & 4.75 & $41.64-42.31$ \\
& Systematicity & 23 & 55 & 36.94 & 4.67 & $36.61-37.27$ \\
& Self-confidence & 23 & 57 & 39.56 & 4.84 & $39.22-39.90$ \\
& Inquisitiveness & 28 & 60 & 43.37 & 5.50 & $42.98-43.76$ \\
& Maturity & 10 & 59 & 36.97 & 5.78 & $36.56-37.38$ \\
\hline Caring Behavior & Total & 206 & 364 & 275.29 & 26.02 & $273.46-277.12$ \\
\hline Helping the patient through the illness trajectory & & & & & \\
& Knowing the patient & 0 & 30 & 18.19 & 5.29 & $17.81-18.56$ \\
& Patient advocacy & 0 & 27 & 15.56 & 4.97 & $15.21-15.91$ \\
& Total & 0 & 27 & 16.41 & 4.99 & $16.06-17.77$ \\
\hline
\end{tabular}

Table 2. Frequencies of learning styles.

\begin{tabular}{ccc}
\hline Learning Style & $n$ & $\%$ \\
\hline Active-reflective & & \\
\hline Active & 446 & 57.4 \\
Reflective & 331 & 42.6 \\
\hline Sensing-intuitive & & \\
\hline Sensing & 588 & 75.7 \\
Intuitive & 189 & 24.3 \\
\hline Visual-verbal & & \\
\hline Visual & 705 & 90.7 \\
Verbal & 72 & 9.3 \\
\hline Sequential-global & & 39.3 \\
Sequential & 305 & 60.7 \\
Global & 472 &
\end{tabular}

distinguishes between visual and verbal learners, 705 $(90.7 \%)$ were found to be visual learners and 72 students $(9.3 \%)$ were identified as verbal learners. Finally, for the fourth dimension, 305 respondents $(39.3 \%)$ were found to be sequential learners, and $472(60.7 \%)$ were global learners.

\subsection{Relationship between Critical Thinking Dispositions and Learning Styles}

Student's $t$-tests were used to test the relationship between scores on the CTDI subscales and students' reported learning styles. As seen in Table 3, the levels of critical thinking disposition differed significantly among the learning styles. The reflective learning style group had a significantly higher overall mean critical thinking score (278.06) than did the active learning style group (273.24), and the global learning style group had a significantly higher overall mean critical thinking score (276.96) than did the sequential learning style group
(272.72).

For the subscales of critical thinking disposition, the reflective learning style group had a significantly higher disposition toward systematicity (37.48) and maturity (37.57) than did the active learning style group (36.53, $36.52)$; the intuitive learning style group had a significantly greater disposition toward self-confidence (40.60) than did the sensing learning style group (39.23); and the global learning style group had a significantly greater disposition toward open-mindedness (41.47) and inquisitiveness (43.69) than did the sequential learning style group $(40.48,42.88)$.

\subsection{Relationship between Critical Thinking Dispositions and Caring Behaviors}

The results indicated a significant positive relationship between overall critical thinking dispositions and caring behaviors $(r=0.23, p<0.01)$. Most critical thinking characteristics, with the exception of maturity, were correlated positively with ratings of caring behaviors (Table 4). This indicated that those nursing students with a greater frequency of caring behaviors reported more positive dispositions toward critical thinking.

\section{DISCUSSION}

In this study, the overall mean CTDI score was 275.29, which was lower than the suggested mean score of 280 set by Facione et al. [17]. In other words, the students in this study showed a marginally weak positive disposition toward critical thinking. This finding was similar to that found in research conducted in Singapore $(M=278.40)$ [4], Hong Kong $(M=268.36)$ [25], and mainland China $(M=272.82)$ [5]. These scores, however, were lower than those found by Profetto-McGrath [26], who studied 
Table 3. Student's $t$-tests for the CTDI subscales and learning styles $(N=777)$.

\begin{tabular}{|c|c|c|c|c|c|c|c|c|c|}
\hline \multirow{2}{*}{ Variable } & & Overall CTD & Truth-seeking & Open-mindedness & Analyticity & Systematicity & Self-confidence & Inquisitiveness & Maturity \\
\hline & $n$ & $M(S D)$ & $M(S D)$ & $M(S D)$ & $M(S D)$ & $M(S D)$ & $M(S D)$ & $M(S D)$ & $M(S D)$ \\
\hline Active & 446 & $273.24(25.81)$ & $35.04(5.61)$ & $40.81(5.12)$ & $41.71(4.77)$ & $36.53(4.53)$ & 39.48 (4.96) & $43.14(5.54)$ & $36.52(5.73)$ \\
\hline Reflective & 331 & $278.06(26.08)$ & $35.85(6.00)$ & $41.46(5.10)$ & $42.34(4.71)$ & $37.48(4.81)$ & 39.67 (4.68) & 43.69 (5.44) & $37.57(5.81)$ \\
\hline t-value & & $-2.567^{*}$ & -1.935 & -1.745 & -1.838 & $-2.821^{* *}$ & -.537 & -1.380 & $-2.502^{*}$ \\
\hline Sensing & 588 & $274.70(26.07)$ & $35.35(5.65)$ & $40.96(5.15)$ & $42.01(4.87)$ & $36.92(4.65)$ & $39.23(4.93)$ & 43.29 (5.59) & $36.95(5.77)$ \\
\hline Intuitive & 189 & $277.13(25.83)$ & $35.5(6.22)$ & 41.47 (4.99) & $41.87(4.37)$ & $37.00(4.75)$ & $40.60(4.41)$ & $43.65(5.20)$ & $37.04(5.85)$ \\
\hline t-value & & -1.118 & -0.332 & -1.192 & 0.367 & -0.213 & $-3.402^{*}$ & -0.783 & -0.196 \\
\hline Visual & 705 & $274.86(25.20)$ & $35.33(5.68)$ & $41.05(5.06)$ & $41.90(4.59)$ & 36.89 (4.58) & 39.53 (4.68) & 43.29 (5.41) & $36.87(5.64)$ \\
\hline Verbal & 72 & $279.51(32.90)$ & 35.94 (6.85) & $41.40(5.68)$ & $42.76(6.08)$ & $37.42(5.52)$ & $39.83(6.25)$ & $44.24(6.25)$ & $37.92(7.04)$ \\
\hline t-value & & -1.447 & -0.859 & -0.553 & -1.474 & -0.914 & -0.498 & -1.399 & -1.459 \\
\hline Sequential & 305 & $272.72(25.73)$ & $35.00(5.75)$ & $40.48(5.07)$ & $41.59(4.73)$ & $36.62(4.35)$ & $39.26(4.55)$ & $42.88(5.21)$ & $36.88(6.05)$ \\
\hline Global & 472 & $276.96(26.09)$ & $35.64(5.81)$ & 41.47 (5.12) & $42.23(4.75)$ & $37.134(4.87)$ & $39.76(5.02)$ & $43.69(5.61)$ & $37.03(5.61)$ \\
\hline t-value & & $-2.223^{*}$ & -1.495 & $-2.651^{*}$ & -1.817 & -1.507 & -1.405 & $-2.007^{*}$ & -0.355 \\
\hline
\end{tabular}

${ }^{*} p<0.05 ;{ }^{* *} p<0.01$.

Table 4. Partial correlation coefficients: CTD subscales and caring behaviors $(N=777)$.

\begin{tabular}{|c|c|c|c|c|c|c|c|c|}
\hline Variable & $\begin{array}{l}\text { Overall } \\
\text { CTD }\end{array}$ & Truth-seeking & Open-mindedness & Analyticity & Systematicity & $\begin{array}{c}\text { Self- } \\
\text { confidence }\end{array}$ & Inquisitiveness & Maturity \\
\hline Caring behavior & $0.23^{* *}$ & & & & & & & \\
\hline $\begin{array}{l}\text { Helping the patient through } \\
\text { the illness trajectory }\end{array}$ & $0.23^{* *}$ & $0.10^{* *}$ & $0.14^{* *}$ & $0.23^{* *}$ & $0.22^{* *}$ & $0.30^{* *}$ & $0.26^{* *}$ & -0.02 \\
\hline Knowing the patient & $0.20^{* *}$ & $0.08^{*}$ & $0.08^{*}$ & $0.19^{* *}$ & $0.19^{* *}$ & $0.28^{* *}$ & $0.23^{* *}$ & -0.02 \\
\hline Patient advocacy & $0.20^{* *}$ & $0.09^{*}$ & $0.11^{* *}$ & $0.19^{* *}$ & $0.19^{* *}$ & $0.25^{* *}$ & $0.22^{* *}$ & -0.03 \\
\hline
\end{tabular}

${ }^{*} p<0.05 ;{ }^{* *} p<0.01$.

649 undergraduate baccalaureate nursing students, enrolled in a 4-year program in Western Canada, whose mean CTDI score was $312.3(S D=36.4)$. These scores also were lower than those of Facione et al.'s college student participants, who had a mean CTDI score of $298.22(S D=27.4)$ [19].

When the findings of this study were compared to those of Facione et al. [19] and Profetto-McGrath [26], all the scores for the subscales were found to be lower than those of the other two. This may be related to Chinese education being different from that of Western countries. In traditional Chinese culture, education is influenced by Confucianism, which emphasizes compliance with authority. Yeh and Chen [7], in a study conducted in Taiwan, posited that the low scores on critical thinking dispositions may have been the result of students having been educated in the philosophy of the Chinese, specifically, the orientation toward control and regimentation [27]. Additionally, the differences in findings between the present and earlier research may have resulted from the sample having different characteristics (e.g., age, maturity level) from the samples used in earlier studies.

In addition, examination-oriented teaching also may have contributed to the low scores. Even so, both the present study and Profetto-McGrath's [26] research found that the scores for disposition of critical thinking for higher-year students were higher than those of loweryear students. However, in both Profetto-McGrath's and this study, there are no statistically significant differences between these two groups for scores on disposition of critical thinking. Yeh and Chen indicated that age could be a contributing factor to critical thinking dispositions [7]. The present study, however, found that disposition toward critical thinking was not age-related. In this study, CTDI scores ranged from 206 to 364; 489 students (62.93\%) scored below 280, 280 students (36.04\%) scored between 280 - 350, and only 8 students $(0.01 \%)$ scored above 350. According to Colucciello [1], "critical thinking dispositions are essential for the development of higher-order critical thinking and learning" (p. 295); as such, these students need more training in critical thinking.

The highest mean score among the seven CTDI subscales was for inquisitiveness (43.37). This finding is similar that of Profetto-McGrath $(M=48.9)$ [26] and Vivien et al. $(M=484.4)$ [4], although the mean scores in these two studies were higher than those found in the present study. Scores between 40 and 50 reflect a positive inclination toward inquisitiveness [19], showing that 
students have curiosity and an eagerness to learn, even when the knowledge may not be of immediate usefulness. It is crucial to nursing practice that students maintain their curiosity in the pursuit of knowledge [26]. As Facione et al. stated [19], "A deficit in inquisitiveness would signal a fundamental limitation of one's potential to develop expert knowledge and professional practice ability" (p. 4). Thus, nursing educators need to promote student curiosity and the desire to learn and to improve.

In this study, the lowest mean score for the seven CTDI subscales was for truth-seeking (35.39). This result reflects an ambivalent or negative inclination toward truth-seeking $[17,19,20]$, a finding similar to that of Profetto-McGrath [26] and Vivien et al. [4]. Our mean scores, however, were somewhat lower than those found in Profetto-McGrath's [26] study of undergraduates in Western Canada (36.4) but higher than those found by Vivien et al. [4] in research on students in a nursing training program (Year $1=28.7$, Year $2=29.6$ ) in Singapore. Nevertheless, it is disturbing that student nurses had a low score on truth-seeking. Truth-seeking indicates an eagerness to seek the best knowledge for a given context, and one should remain "receptive to giving serious consideration to additional facts, reasons, or perspectives even if this should necessitate changing one's mind on some issue" (p. 6) [19]. A deficit in truth-seeking among nurses could imperil the health of their clients.

This weakness in truth-seeking could be due to the time constraints of courses and to didactic-oriented teaching [28]. In Taiwan, examination-oriented teaching results in the teacher providing a great deal of information in the lecture, taking away from time for student questions and discussion. Students also may take a passive stance, which limits the opportunity for exchange of knowledge with classmates.

The most common dimensions of the four learning styles were found to be active, sensing, visual, and global. According Felder and Spurlin [21], this implies that students are likely to learn by trying things, working in groups, using a concrete and practical orientation toward facts and procedures, working with visual representations of presented material, and using holistic thinking processes, enabling them to learn in large leaps. This finding was most similar to that of research conducted in China by Zhang and Lambert [5], with the exception of the active-reflective dimension. Zhang and Lambert [5] suggested that Chinese nursing students prefer to learn through reflection. The students in the present study, however, tended to be active learners. This difference may be the result of differences between the Taiwanese and Chinese educational systems.

Students with a reflective learning style had higher systematicity and maturity scores on the CTDI than did those with an active learning style; students with an in- tuitive style had higher self-confidence scores on the CTDI than did those with a sensing learning style; and students with a global learning style had higher openmindedness and inquisitiveness scores on the CTDI than did those with a sequential learning style. This suggests that those who learn through a reflective style are inclined to be organized, orderly, focused, and diligent in solving problems and prudent in making, suspending, or revising judgment when making complex decisions. Those who learn through an intuitive style tend to trust their own reasoning process, and those who learn through a global style tend to be tolerant of divergent views and sensitive to own bias and are inclined toward intellectual curiosity and a desire to learn [2,19].

Student nurses display midlevel caring behavior. Similar results have been found in Taiwan [24]. These findings may result from "vocational education and training" that focuses on technical manipulation aspects of the nursing program. The psychosocial dimensions of their education, however, do not arise from the general curriculum. Therefore, Taiwanese nursing students who receive "vocational education and training" need courses that help educate them in these dimensions of caring, which serve as the core of nursing.

Another main significant positive relationship between critical thinking characteristics, with the exception of the maturity dimension, and caring behavior was found in this study. That is, students who had a greater willingness to help the patient through the illness trajectory, better knowledge and understanding of the patient, and greater advocacy of patients' rights tended to display truth-seeking, open-mindedness, analyticity, systematicity, self-confidence, and inquisitiveness. Thus, students with greater caring behaviors reported more positive critical thinking disposition. These results support the view of Watson [29] (1990) that caring is the core of nursing practice and are consistent with research that demonstrates the important role of caring in critical thinking $[10,12]$. This implies that caring motivates students to listen to and to consider patient demands, which provides a foundation for critical thinking and the provision of high-quality care. This finding is also supported by the perspective of Redding [14], who described caring as involving the integration of internal and external sources of information and taking valid action through holistic critical thinking.

\section{CONCLUSIONS}

In the fast-paced and complex healthcare environment, with its emphasis on providing care as quickly as possible, the positive dispositions of critical thinking are crucial for clinical practice. This study identified the relationship between caring behavior and critical thinking 
dispositions, which strengthed the body of knowledge for the core of caring.

Our results reflect the students' preferences for active, sensing, visual, and global learning styles. The findings also indicate, however, that students who are reflective, intuitive, and global learners have more positive critical thinking characteristics (systematicity, maturity, self-confidence, open-mindedness, and inquisitiveness). These results suggest that changing learning style to a reflective, intuitive, and global one will promote a positive disposition toward critical thinking. Additionally, the findings indicate that caring behavior is an effect factor in the disposition toward critical thinking and good judgment for students, enabling nursing students to touch the heart of patients through the students' caring behaviors and to meet the complicated needs of patients.

Although future research is needed, these findings appear to indicate that caring behaviors and learning style are essential for a positive disposition toward critical thinking. With caring and individual learning style as a staring point, teachers can focus on students' caring behavior and learning style as a means to enhance their positive disposition toward critical thinking. In addition, longitudinal studies investigating the relationship between caring and critical thinking dispositions as well as the change in student nurses' disposition towards critical thinking across the five years of the program are also needed.

\section{STUDY LIMITATIONS}

The generalizability of the findings is limited by the use of a convenience sample and a cross-sectional design. Therefore, future research should use a random sample or a wider geographic region from which to draw participants and utilize a longitudinal design. Additionally, the self-report design created the potential for social desirability bias. While the study showed a significant positive relationship between caring behavior and disposition toward critical thinking, the correlation coefficient was relatively low, which suggests the need for more research to support this finding. In addition, although the ILS (Chinese version) had a reliability above 0.50 , suggested by Felder and Spurlin as indicative of adequacy, the reliability was still relatively weak. However, it also is possible that the low reliability was due to the scale's lack of cultural sensitivity to Chinese students, as the scale was developed in a Western culture. In either case, further research is needed to ensure that the ILS (Chinese version) is more culturally sensitive in assessing the learning styles of Chinese students. Finally, this study did not compare the characteristic of students as related to critical thinking disposition, caring behavior, or learning styles. Such a comparison is recommended for future research.

\section{REFERENCES}

[1] Colucciello, M.L. (1999) Relationships between critical thinking dispositions and learning styles. Journal of Professional Nursing, 15, 294-301. doi:10.1016/S8755-7223(99)80055-6

[2] Suliman, W.A. (2006) Critical thinking and learning styles of students in conventional and accelerated programmes. International Nursing Review, 53, 73-79. doi:10.1111/j.1466-7657.2006.00445.x

[3] Thompson, C. and Crutchlow, E. (1993) Learning style research: A critical review of the literature and implications for nursing education. Journal of Professional Nursing, 9, 34-40. doi:10.1016/8755-7223(93)90084-P

[4] Vivien, W.X., Tham, L.K.C., Lau, S.T.L., Mei, T.-T.Y. and Kiat, T.K. (2010) An exploration of the critical thinking dispositions of students and their relationship with the preference for simulation as a learning style. Singapore Nursing Journal, 37, 25-33.

[5] Zhang, H. and Lambert, V. (2008) Critical thinking dispositions and learning styles of baccalaureate nursing students from China. Nursing \& Health Sciences, 10, 175-181. doi:10.1111/j.1442-2018.2008.00393.x

[6] Yu Chao, Y.-M., Dai, Y.-T. and Yeh, M.-C. (2010) Perspectives on nursing education, licensing examinations and professional core competence in Taiwan in the context of globalization. The Journal of Nursing Education, 57, 5-11.

[7] Yeh, M.-L. and Chen, H.-H. (2003) Comparison of affective dispositions toward critical thinking across Chinese and American baccalaureate nursing students. Journal of Nursing Research, 11, 39-46. doi:10.1097/01.JNR.0000347617.29413.96

[8] Yeh, M.-L., Chen, H.H. and Huang, J.-P. (2009) Affective dispositions toward critical thinking in college-level nursing students. Journal of Nursing and Healthcare Research, 5, 193-200.

[9] Dunn, R. (1984) Learning style: State of the science. Theory into Practice, 23, 10-19. doi:10.1080/00405848409543084

[10] Thayer-Bacon, B.J. (1993) Caring and its relationship to critical thinking. Educational Theory, 43, 323-340. doi:10.1111/j.1741-5446.1993.00323.x

[11] Watson, J. (1987) Nursing on the caring edge: Metaphorical vignettes. Advances in Nursing Science, 10, 10-18.

[12] Zimmerman, B.J. and Phillips, C.Y. (2000) Affective learning: Stimulus to critical thinking and caring practice. Journal of Nursing Education, 39, 422-425.

[13] Swanson, K.M. (1993) Nursing as informed caring for the well-being of others. Journal of Nursing Scholarship, 25, 352-357. doi:10.1111/j.1547-5069.1993.tb00271.x

[14] Redding, D.A. (2001) The development of critical thinking among students in baccalaureate nursing education. Holistic Nursing Practice, 15, 57-64.

[15] Peng, M., Wang, G. and Chen, J. (2004) Validity and reliability of the Chinese critical thinking disposition inventory. Chinese Journal of Nursing, 39, 644-647. 
[16] Facione, N.C., Facione, P.A. and Sanchez, C.A. (1994) Critical thinking disposition as a measure of competent clinical judgment: The development of the California critical thinking disposition inventory. The Journal of Nursing Education, 33, 345-350.

[17] Facione, P.A., Facione, N.C. and Giancario, C.A.F. (2000) The California critical thinking disposition inventory, CCTDI scoring supplement. The California Academic Press, Millbrae.

[18] Facione, N.C. (1997) Critical thinking assessment in nursing education programs: An aggregate data analysis. The California Academic Press, Millbrae.

[19] Facione, P.A., Sánchez, C.A., Facione, N.C. and Gainen, J. (1995) The disposition toward critical thinking. Journal of General Education, 44, 1-25.

[20] Felder, F.M. and Soloman, B.A. (1991) Index of learning styles. North Carolina State University, Raleigh. http://www4.ncsu.edu/unity/lockers/users/f/felder/public/ ILSdir/ILS-a.htm

[21] Felder, R.M. and Spurlin, J. (2005) Applications, reliability and validity of the index of learning styles. International Journal of Engineering Education, 21, 103-112.

[22] Student Learning Support Section (2007) Index of learning styles (Chinese version). Tamkang University, Taipei. http://sls.tku.edu.tw/WEB/CHT/index.html
[23] Lin, P.F. (2001) Development and psychometric evaluation of the caring behaviors scale of baccalaureate nursing student in Taiwan. Ph.D. Thesis, Boston College School of Nursing, Boston.

[24] Ou, S.F. (2006) Lin PF: Study of the caring behavior of nursing students in a 5-year junior college. Tzu Chi Nursing Journal, 5, 80-89.

[25] Tiwari, A., Avery, A. and Lai, P. (2003) Critical thinking disposition of Hong Kong Chinese and Australian nursing students. Journal of Advanced Nursing, 44, 298-307. doi:10.1046/j.1365-2648.2003.02805.x

[26] Profetto-McGrath, J. (2003) The relationship of critical thinking skills and critical thinking dispositions of baccalaureate nursing students. Journal of Advanced Nursing, 43, 569-577. doi:10.1046/j.1365-2648.2003.02755.x

[27] Fairbank, J.K., Reischauer, E.O. and Craig, A.M. (1989) East Asia: Tradition and transformation. 2nd Edition, Houghton Mifflin, Boston.

[28] Colucciello, M.L. (1997) Critical thinking skills and dispositions of baccalaureate nursing students-A concepttual model for evaluation. Journal of Professional Nursing, 13, 236-245. doi:10.1016/S8755-7223(97)80094-4

[29] Watson, J. (1990) Caring knowledge and informed moral passion. Advanced in Nursing Science, 13, 15-24. 